University of Nebraska - Lincoln

DigitalCommons@University of Nebraska - Lincoln

German Language and Literature Papers

Modern Languages and Literatures, Department

Spring 2004

\title{
Well-Structured Texts Help Second-Year German Students Learn to Narrate
}

Priscilla A. Hayden-Roy

University of Nebraska-Lincoln, phayden-roy1@unl.edu

Follow this and additional works at: https://digitalcommons.unl.edu/modlanggerman

Part of the Modern Languages Commons

Hayden-Roy, Priscilla A., "Well-Structured Texts Help Second-Year German Students Learn to Narrate" (2004). German Language and Literature Papers. 27.

https://digitalcommons.unl.edu/modlanggerman/27

This Article is brought to you for free and open access by the Modern Languages and Literatures, Department of at DigitalCommons@University of Nebraska - Lincoln. It has been accepted for inclusion in German Language and Literature Papers by an authorized administrator of DigitalCommons@University of Nebraska - Lincoln. 


\title{
Well-Structured Texts Help Second-Year German Students Learn to Narrate
}

\author{
Priscilla Hayden-Roy \\ University of Nebraska-Lincoln
}

\section{Language Proficiency and Narration}

The past twenty years have seen a significant paradigm shift in foreign language pedagogy from measuring language achievement (based on a defined and finite curriculum, such as a textbook chapter or a grammar lesson) to measuring proficiency (general competence in the foreign language independent of a defined curriculum). Building on the work done previously in language testing by government language schools, the ACTFL Proficiency Guidelines (1986) sought to reach consensus about describing and measuring language abilities. These Guidelines give generalized descriptions of abilities at four levels of proficiency (Novice, Intermediate, Advanced, Superior). With the widespread recognition of these Guidelines have come far-reaching changes in our approach to foreign language instruction. Proficiency baselines have been put forward for the first years of college instruction, and some institutions have tied proficiency standards to their language requirement or to their major. Proficiency guidelines are also changing our approach to curricular design. By understanding the range of abilities at each level of proficiency, we can shift the emphasis of instruction as students progress to allow for the development of the recommended skills. This article will investigate the implications of the Proficiency Guidelines for second-year German curricular design, looking specifically at the standards for the Advanced level (narration of concrete and factual topics in paragraph length discourse). We will then consider how the development of this skill can become a central emphasis of the second-year curriculum by requiring students to summarize the texts they read in class. As text selection plays a critical role here, we will discuss recent research by cognitive psychologists on how we learn from texts, which points to the importance of text structure in facilitating recall. We will then give an overview of some of the materials we have developed for second-year German at the University of Nebraska, and present examples of the scaffolded activities we use in preparing our students to summarize the texts.

The proficiency level for most second-year students of German has reached a plateau at the Intermediate level. Research indicates that students move quickly from the Novice to the Intermediate level in the first year of instruction, but then move much more slowly to the Advanced level. In a study of the first- and second-year German program at the University of Michigan, Erwin Tschimer found that $96 \%$ of the students had reached the Intermediate level after two semesters of German, with over $80 \%$ at Intermediate-Mid or higher. However after four semesters, nearly $95 \%$ were still at the Intermediate level, with over $60 \%$ at Intermediate-Mid or lower. It might well be unrealistic to expect a two-year university program to bring the majority of students beyond Intermediate-Mid. ${ }^{1}$ But when one looks at the curriculum for the second year with an eye to the Advanced level, one must ask if this curriculum is designed specifically to encourage the development of Advanced-level skills. We recall some of the features of the Intermediate, Advanced, and Superior levels according to the ACTFL Guidelines:

1. Tschimer relates that at the University of Pennsylvania the exit requirement after two years of study was IntermediateHigh. But this had to be lowered to Intermediate-Mid "because otherwise too few students would have passed" (14). 


\section{Global Tasks/Functions:}

Intermediate: can maintain simple face-to-face conversations by asking and responding to simple questions

Advanced: can describe and narrate in major time/ aspect frames

Superior: can discuss extensively by supporting opinions, abstracting and hypothesizing

\section{Content:}

Intermediate: topics related primarily to self and immediate environment

Advanced: concrete and factual topics of personal and public interest

Superior: wide range of general interest topics and some special fields of interest and expertise; concrete, abstract and unfamiliar topics

Text Type:

Intermediate: discrete sentences and strings of sentences

\section{Advanced: paragraph discourse}

Superior: extended discourse

We see that the main distinction between the Intermediate and Advanced levels lies in the ability to convey a whole paragraph of concrete or factual information, rather than discrete sentences. On the other hand the Advanced-level speaker is not yet able to talk extensively on unfamiliar or hypothetical topics, or to formulate an argument with supporting opinions. Typically second-year students of German are unable to narrate an episode, be it from a film, a book, or an incident from their lives. The ability to tell a story presents an enormous hurdle at this level, and it is a key skill students must master on their way to the Advanced level. But too frequently second-year textbooks do not focus on developing this skill through classroom activities and assignments. While the texts (in the broadest sense: written texts, audio recordings, or videos) used in these textbooks might well lend themselves to this kind of work, activities tend to go in two directions. First, students are asked to answer sentence-length responses to the texts (answering content-based questions); these typically are given as homework along with the reading assignment. At best we find that students have comprehended the text as a result of this exercise. But in many cases they will have used what Lee and Musumeci have called the "look back strategy" (183) of matching question wording with textual wording, without having understood any of it. In any case, they are only able to work with the text if it is in front of them, and they are far from being able to produce a summary of it with few or no prompts. The second level of activities typically moves students to higher-level analysis of the text: compare and contrast, argue an opinion. If students move directly from the comprehension questions to analysis, then they never must go through the process of mastering the vocabulary and syntax to the degree required when summarizing the text. This amounts to a missed opportunity, a failure to exploit fully the language learning each text offers us. Our goal here is not mere comprehension. Comprehension is certainly the first step. But with the next step, mastering a detailed summary in the foreign language, students must learn far more deeply from the language mediating their comprehension, than is the case either with answering content questions or giving their opinions on the text. Through this process they internalize, often through implicit rather than explicit learning, a wealth of vocabulary, syntax, and grammar. Moreover their ability to retain not just words or sentences, but whole narrative sequences in the foreign language, is being systematically stretched through this activity. This ability is of course key to producing paragraph-length discourse and thus to perform at the Advanced level. Clearly the students cannot yet sustain this Advanced-level discourse, but by repeatedly requiring summaries of them, they are gaining practice at it. Through carefully selected texts and activities, the classroom provides them with a setting that is highly controlled, both in terms of content and expectations relating to grammar and syntax, so that with some effort students can master this very limited instance of Advanced-level discourse, rather than breaking down.

\section{How Text Structure Affects Recall and Narration}

The success of this emphasis on summarizing in the foreign language will depend in large part on the kind of text one selects. This brings us to a cognitive question: what sort of texts facilitate retention and recall? Recent research in cognitive psychology has investigated the very complicated question of how we learn 
from texts, and has found that the text's structure has a measurable impact on comprehension and recall. Several aspects of text organization have been examined, ${ }^{2}$ including causal structure (Trabasso and van den Broek), hierarchical structure (van den Broek), the presence of a "story grammar" (Mandler and Johnson, Thorndyke) and the degree to which this grammar is followed in the presentation of the text (Mandler), and, closely related to this, the presence of culture-specific schemata (Kintsch, Kintsch and Greene), and finally the discourse type (Meyer and Freedle). I summarize briefly below some of the conclusions of this research.

Research examining causal structures and comprehension has found that events on the causal chain and events with a greater number of connections to other events are recalled better than "dead-end" events not leading to subsequent developments in the text, and events with a low number of connections to other events (Trabasso and van den Broek).

Readers tend to recall material associated with the main goal better than that associated with subordinate goals: "Statements that are high in a hierarchical representation are more important than those low in the hierarchy. Higher-level statements are recalled and summarized more frequently" (van den Broek 2).

Recall is enhanced when the narrative follows a familiar "story grammar" or "story schema." A story grammar is a general structural framework which the reader has learned through previous reading, and which he then applies to the text at hand. Thorndyke has defined the elements as: setting (characters, location, time), theme (states the goal for the main character to achieve), plot (episodes, in which the main character strives to achieve the goal), and resolution (attainment of goal or statement of response of main character to final state of affairs) (80). Thorndyke concludes:

When the narrative structure was readily inferable due to repetition and redundancy in the text $[. .$.$] , subjects could readily pro-$ duce an organizational hierarchy for the plot and use it to encode the information from the passage. Such stories were rated easy to comprehend and produced high recall. A more densely structured plot with no repetition [...] produced lower comprehensibility ratings and recall proportions, indicating that subjects encountered more difficulty producing the integrating framework for the passage. (104)

Mandler has taken this idea a step further and compared recall of a simple two-episode story when it was presented according to the standard story grammar (each episode is related as a unit, with setting, beginning, development, reaction, goal, and end), and when it was presented in an interleaved version, where the narrative switches back and forth, giving first the two settings, then the two beginnings, then the two reactions, etc. She found that among adult subjects the quantity of recall of both the standard and the interleaved version of the stories was about the same, but the quality "lack of repetitions and distortions" was greater when recalling the standard version. Moreover, subjects tended in their recollections to alter the interleaved version in the direction of the standard version, joining together the pieces that had been separated through the interleaving. This suggests, argues Mandler, that subjects tend to store the story in their memory according to the standard schema (34). Mandler also found that in contrast to her adult subjects, children in the fourth and sixth grades recalled quantitatively less of the interleaved stories than of the standard texts.

Kintsch, and Kintsch and Greene, have argued that story schemata are culture-specific and that stories following a familiar story schema will be easier to comprehend than those that do not. They found that US college students were far more successful in summarizing an episode from the Decameron, or a Grimm fairy tale with a "highly conventional" story structure, than they were when given an Apache Indian tale. The familiar structure of a single hero and a "complication-resolution principle" facilitated recall of the Decameron tale and the fairy tale. By contrast, the events in the Indian story were "not always causally related, they did not follow the complication-resolution principle, and there was no single hero to give the story continuity. These violations of their expectations confused the readers and made it difficult or impossible for them to organize the story, that is, to construct a macrostructure" (Kintsch 381). Similarly Thorndyke has observed, "insofar as people are able to identify a particular story as an example of a general, previously learned organizational framework, they use that framework to comprehend and encode the information in a particular text" (79).

2. A succinct summary and overview of the research on causal structure, story grammar and hierarchical levels can be found in Horiba, van den Broek and Fletcher (48-53). 
Finally, Meyer and Freedle have examined the effects of discourse type on recall. They identified four typical organizational structures for prose texts: comparison, problem/solution, causation, and a collection of descriptions. They argue that the collection of descriptions presents the least structured form of discourse and found that quantity of recall of this type of text was lower than for the other, more highly structured types of discourse.

The research cited above was all conducted on subjects reading or listening to texts in their native language. However researchers recently have applied this research to the field of second language learning. For example, Carrell repeated Mandler's experiment with adult L2 (ESL) readers, and found that their recall of interleaved stories was both quantitatively and qualitatively poorer than when the two episodes were told as units and in accordance with the standard schematic order (setting and then episode, consisting of beginning, development, and ending). This is in contrast to Mandler, who found that only the quality, but not the quantity, of L1 adult subjects' recall was impacted by the interleaving. Carrell concludes: "Native-speaking adults don't have to devote as much effort to linguistic encoding and can therefore devote more effort to encoding the incoming interleaved stories in their ideal schematic form as two separate episodes, tagged with an interleaving algorithm. Non-native readers who must devote more effort to linguistic encoding have less effort to devote to the sorting of interleaved input into ideal schematic form" (104). She hypothesizes that there may be "less flexibility on the part of ESL learners' retrieval processes when compared to Mandler's native-speaking adults" (104). In this sense they resembled Mandler's fourth- and sixth-graders, whose recall also was hindered through the more complex, interleaved versions of the stories. From these observations follow important implications for foreign language curricular design: if the foreign language learner's ability to recall and retell texts is hindered through a complicated text structure, then the potential for a more detailed, lengthier and linguistically richer retelling will increase when the student must recount a well-structured text that follows a standard schematic order.

In a comparative study conducted on Japanese (L2English) and American (L1-English) readers, Horiba, van den Broek, and Fletcher found that L2 readers availed themselves of organizational structures (causality, story grammar, hierarchy) when recalling stories. They recalled events on the causal chain better than those off the causal chain; and they recalled events with many causal connections better than those with few connections (64). In distinction to the LI readers, however, whose recall was strongly influenced by hierarchical level (main goal events recalled better than events of lower-level goals), this discrimination was less visible in the L2 readers, suggesting, as the authors note, that "hierarchical-level factors may have been too demanding for the L2 reader, whose limited language competence imposed attention allocation to the understanding of immediate relations of individual ideas and events" (65). However the $\mathrm{L} 2$ readers tended to be more attentive to whether or not an event was on or off the causal chain, indicating, that "L2 readers do make use of structural variables to guide their comprehension but ... the multiple demands make them focus on more local structural variables than L1 readers do" (65-66). With regard to story grammar, the authors found that for both L1 and L2 readers, goals and outcomes were most readily recalled (66). ${ }^{3}$

\section{Implications for Text Choice in Curriculum Design}

Horiba, van den Broek, and Fletcher designed their study to determine the degree to which L2 readers used a variety of structural models to inform their reading, particularly in making "top-down" inferences based on these models to "fill in" the gaps that arose when their comprehension broke down. Given that L2 readers are sensitive to text structure, our question is how to apply their research (and the conclusions of other researchers discussed above) to the question of curricular design in second-year foreign language programs. Summarizing their results, we see that L2 readers tend to recall with greatest frequency:

- events on the causal chain

- events with many causal connections

- the goals and outcomes of a narrative

- the overall progression of stories with culturally familiar frameworks (complication-resolution principle, single hero) 
- stories which follow an "ideal schematic form" (setting, then episode, consisting of beginning, development and end)

If we want to maximize the amount of language a student will recall from a text, and if we want to minimize the effort required to hold the representation of the text in their memory, we must select reading materials for the class that exhibit a high degree of the kind of structural organization easily recalled:

- texts with clear causal linkages, where one event necessarily leads to the next, but ideally containing little extraneous information off the causal chain; or

- texts which follow a complication-resolution principle, where a single hero works to achieve a goal through a series of episodes

In general we can say that texts sequentially structured, whether through a causal, hierarchical, or chronological structure, and texts where this organization is clearly or even redundantly stated, will be simplest to recall. ${ }^{4}$ What sort of texts fit this description? One thinks immediately of fables and fairy tales, ballads, detective stories, descriptions of procedures, or discussions of sequentially occurring natural phenomena. What sort of texts, by contrast, do not typically present this sort of sequential structure? Interviews, opinion pieces, abstract or theoretical discussions, literary texts with little action, with difficult-to-follow chronologies (such as flashbacks) come to mind. Admittedly some texts with suitable structures will have linguistic features that make them unusable in second-year instruction. Text selection cannot be reduced to this single criterion, but in most cases should be considered a necessary but not sufficient criterion. Judging texts strictly in terms of their linguistic difficulty, on the other hand, is similarly inadequate when taken by itself, and clearly such measures as the Lix formula offer insufficient guidance in making appropriate text selections, as Bernhardt also has argued (322).

\section{Sample Application: Second Year Assignments and Classroom Activities}

An examination of the instructional materials available for second-year German indicates that text structure generally is not a criterion for text selection, nor does summarizing constitute a central goal in the design of the curriculum. For that reason we decided to design materials with this emphasis for use in our second-year German program at the University of Nebraska. My co-designer, Sabine Koelbl-Mannarelli, and I selected or wrote texts with sequential narrative structures and clear causal links joining the episodes or ideas. We then designed activities and assignments which scaffolded up to the final goal: retelling the story or summarizing the text in German, sometimes orally, sometimes in written form, but in any case without the assistance of notes. These materials have been in use since 1999; currently Aleidine Moeller (University of Nebraska) and I are conducting research on the effects, both quantitative and qualitative, of this method on language acquisition in the second year.

\section{Retelling Picture Stories}

Our first unit begins with a number of e. o. plauen's Vater und Sohn Bildgeschichten. We selected stories that lent themselves to retelling at this level (clear, causally linked actions with high-frequency vocabulary). 5 The stories have no text, so in the first assignments there is no reading involved. We begin with an ordering exercise: in pairs students must order the pictures for the story, "Wie die Jungen zwitschern." In very little time all accomplish

4. In determining what texts are appropriate for the L2 classroom, I believe it is imperative that we give far greater attention to this issue of text structure. It is interesting to note the emphasis on text structure in ACTFL's descriptions of reading comprehension at the Intermediate and Advanced levels. Intermediate Low: "Such texts are linguistically noncomplex and have a clear underlying internal structure, for example chronological sequencing." Intermediate Mid: "Such texts are still linguistically noncomplex and have a clear underlying internal structure." Advanced: "Able to read somewhat longer prose of several paragraphs in length, particularly if presented with a clear underlying structure." Cited by Alison Edwards (359-60); see also her discussion here of the ACTFL criteria as a predictor of relative text comprehensibility.

5. We use "Wie die Jungen zwitschern," "Grenzen der Malerei," "Moral mit Wespen” and "Erziehung mit angebrannten Bohnen." 
this task, and with this active participation and quick success, their affective filter is lowered, their comprehension of the story is guaranteed, and their interest is focused. Now, using an overhead in class, we generate as a class a text for the story in German. A great deal of vocabulary comes from the students; when needed the instructor makes the necessary grammatical corrections before writing the sentences on the board. This battery of sentences provides us with more than enough material for retelling the story. We do several repetitions, chorally and individually, so that by the end of class all are familiar with the vocabulary. Students then practice retelling the story to each other in pairs. For the next class period students must retell the story orally; they do this oneon-one with the instructor. Students have the picture story in front of them, which further assists in their recall. Students may alter phrases or embellish their narrative as they wish, but they must master the basic vocabulary, and, as the emphasis on the first unit is verb forms in the present tense, these, too, must be precise and accurate. Right from the start, then, second-year students are telling a story, producing paragraph-length discourse. Because they are doing so in a highly controlled environment for which they can prepare, they are able to succeed. Obviously they have not achieved the Advanced level, but we are pushing them systematically in that direction.

The selection of picture stories as the basis for our first summarizing assignment presents some advantages to the instructor. All students work from the same visual image, and comprehension issues generally do not arise with these visual "texts." Language production moves directly from image to L2; comprehension barriers that an L2 text might present are avoided, as is the need to mediate comprehension through L1. Because the students have the images in front of them as they narrate the story, their powers of recollection are further relieved, and they can focus solely on language production. Picture stories thus provide an intermediary stage on the way to "mature" recollection of texts, insofar as the memory is disburdened of the task of recalling what comes next. (The cognitive advantages of picture stories, both as visual cues and as sequentially structured narratives, helps explain the recent success of TPRS in foreign language education. $)^{6}$

\section{Retelling Readings}

In the second unit, which features a selection of Aesop's fables and a Grimms' fairy tale, we begin to put more emphasis on reading, but again with the goal of retelling or summarizing the stories. Here, too, text choice was critical. Fables with clear, sequential narratives were selected, where one event hinges on the next, and where the chain of events is central to the point of the fable. We begin with "Der Löwe und das Mäuschen," and again we proceed first from image to story. A series of six pictures illustrates the progression of events in the fable, and we first generate a text using these images on the overhead, as we did with the Vater und Sohn Bildgeschichten. Students are responsible for being able to retell the fable, but are provided with the images to do so. With the next fable we begin with an ordering exercise using the written text. Students receive an envelope containing a brief list of key vocabulary words with English translations, and the fable "Der Adler und die Dohle" cut into five text sections. Students work in pairs to piece together the story. Again the emphasis is on finding and constructing a logical sequence among the narrative pieces. From there we construct as a class a picture story of what happened. These images become the basis for summarizing the text.

\section{Summarizing Longer Stories}

The final exercise with fables pushes students to more independent reading, forming of images, and summarizing. We divide our classes into three groups, and assign each group one of three different fables: either "Der Hund und das Stück Fleisch," "Die beiden Frösche," or "Die weilße Dohle." Students first meet in same-fable groups, after having been given their

6. James C. Davidheiser gives a good general introduction to TPR and TPRS, as well as discussing how he implemented the method in his elementary German classes (2001, 2002). Blaine Ray's TPRS textbooks for German, Look, I Can Talk (Los Gatos, CA: Sky Oaks, 2000), Look, I Can Talk More (Bakersfield, CA, 1997), and Look, I'm Still Talking (Tucson, AZ, 1993) feature picture stories as the starting point for instruction. While these materials can be used effectively and are on the right track in terms of the cognitive issues discussed here, a complete second-year program must also foster reading skills, which these materials do not offer (as Davidheiser has noted, 2001, 59). We then come back to the question of how reading materials for the second year can be selected that offer the same cognitive advantages the picture stories do. 
fable as a reading assignment in the previous class. Here students discuss the text, control for comprehension, work on simplifying the language, and break down the narrative into a clear, visual sequence of actions. The following class students meet in groups of three, all with different fables, and tell their fable to each other. Students may not read their material; only note cards with key words are allowed. But visual aids (pictures, puppets, props of any sort) are encouraged. The student narrating the fable is allowed to give the group a brief list of vocabulary words before beginning with the narration. Those listening may ask for clarification, but questions and answers must be in German. Assessment is based on the notes taken by those listening, and on the note cards and visual aids used by the narrator.

The final text of this unit is fairy tale by the Grimm brothers, the "Bienenkönigin." This text was selected because its structure lends itself to easy recall: the narrative is sequential with clear causal connections between each element of the story, and redundant patterns reinforce the sequencing. ${ }^{7}$ For example, in the first part the following structure is repeated three times: the brothers meet animals, the two elder brothers wish to do them harm, the Dummling intervenes to save them. In the middle section the narrative moves to the enchanted castle and the definition of the three tasks. Again the narrative is redundant in describing the failure of the two elder brothers to complete the first task. The final section relates how the Dummling fulfills each task when each of the animals whom he had saved in the first part of the tale comes to his aid. Here we find a clear causal relationship between the help the animals received in the first part and the assistance they wish to provide as thanks in the last part. Thus each piece of the narrative has a place in a series of redundancies within the text, as well as a causal function in facilitating the resolution of the story. Moreover the narrative follows a familiar complication-resolution structure, where a single hero (the Dummling) works to achieve a goal through a series of episodes. The final goal, marrying the youngest daughter and becoming king, is a consequence of the causally linked episodes that preceded it. The "Bienenkönigin" is built around patterns and structures that facilitate recall, and there are very few details or events in the story that are extra- neous to these patterns and structures. Thus it is ideally suited for use in our curriculum, where we need a text that is sufficiently long and detailed to challenge the students linguistically when they summarize it, but whose structure facilitates extensive and detailed recall. Homework assignments relating to the "Bienenkönigin" are designed to guide the student's reading from comprehension to summarizing. In order to ensure that students really are reading the text and gaining their initial comprehension of it through their reading, rather than from class discussion, we ask that they produce for each half of the story (assigned on two separate days) a graphic organizer based on their reading. Students use a grid of fifteen boxes to draw a series of simple sketches illustrating the main ideas of the text and then label each picture with key words or phrases. Students enjoy this assignment, although very time-consuming, because it draws on their creativity and their own visualizations of the story. Moreover their comprehension is generally very detailed and accurate, more so than would be the case if a series of content questions had been assigned. In the next class students are ready to work in pairs, using their own illustrations to retell the story. At this point questions regarding the meaning of certain passages arise, and relevant vocabulary has surfaced through the students' own efforts. Now the class is ready to generate its own retelling of the story, which the instructor solicits from individuals and write on the board. Subsequent homework assignments reinforce vocabulary: grammar exercises are drawn from the text and recycle important vocabulary; multiple choice, cloze, and short-answer questions reinforce content. Practice retelling the fairy tale in class culminates with a group summary. Sitting in a circle, each member of the class contributes a sentence to the story without the use of any visual or written aids. Because of the fairy tale's structure, it is rare that students omit events, and the retelling proceeds with very little prodding or cuing from the instructor. This class summary gives the students the confidence for the next step, which is to write a summary of the fairy tale on their test. They receive a list of about thirty words essential for the retelling of the fairy tale; the words are given in English and in the order they occur in the story. In thirty minutes the students must write a summary using at least twenty

7. Interestingly, Kintsch and Greene (1978) use this same fairy tale as an example of a story with a "highly conventional" structure, in their examination of the effects of culture-specific schemata on comprehension and recall of stories (7-13). 
of the vocabulary words. Because of the preparatory work we have done in class, and, more importantly, because we are working with a text that, due to its structure, is relatively easy to recall, even the weakest students are able to succeed. And there comes with this a great feeling of accomplishment: "I just summarized a whole Grimm's fairy tale! Not bad for thirdsemester German!"

From the instructor's point of view, the students have succeeded at another level as well. The German in these summaries is markedly better than what students generally write on their tests in response to their readings. One finds a larger and more precise vocabulary, control of tense is more consistent, syntax is more sophisticated, even word order tends to be better than average. Moreover the length and detail of these summaries is unusual for this level, an indication that, with careful text selection and scaffolding of activities in the classroom, students can stretch their ability to retain and recall extended narrative sequences even at this level.

\section{What about Grammar?}

In our second-year curriculum we try as much as possible to teach grammar based on the reading material. While each text we discuss and retell could lead to a host of grammatical discussions, we have given each unit a grammatical focus and have chosen texts that lend themselves to a discussion of this particular point of grammar, in addition being suitable for retelling. For example, the grammatical focus of the Vater und Sohn Bildgeschichten is narration in the present tense. In the second unit we focus on the imperfect. In each case the texts provide a wealth of examples of these points, and we focus on having the students learn the forms as they appear in the stories, rather than on practicing the paradigm in isolation from a context. Later in the first semester we discuss Janosch's Oh, wie schön ist Panama, at the same time covering the two-way prepositions. The text and especially the illustrations offer many opportunities to practice these, while at the same time reinforcing the story line and vocabulary. For the second semester we developed a series of texts on the envi- ronment that feature the passive voice. Again, exercises reinforce the central ideas of the texts as well as practicing the passive. Of course in every unit, the texts the students are summarizing contain a broad range of grammatical and syntactical problems that are not being taught explicitly in the classroom. But because the method requires summarizing and retelling, the students do a great deal of implicit learning as they become familiar with the stories. Thus this method advocates a hybrid model for teaching grammar, where we exploit the advantages of explicit and implicit learning but situate both kinds of learning in a larger linguistic goal, which is the process of learning to recall and retell texts in German.

\section{Conclusion}

Narrative structures affect comprehensibility and recall. Culturally familiar and simple, but authentic, narrative structures provide important affective and cognitive support to students learning the skill of narration. ${ }^{8}$ Summarizing well-structured texts brings with it a wealth of benefits to the process of learning a second language, from mastery of vocabulary and syntax, to implicit learning of unfamiliar structures, to gaining cultural literacy through the content itself. And when clear, familiar text structures assist their recall, Intermediate-level students can begin producing whole paragraphs in the foreign language, thus gaining confidence and practice in their progress toward the Advanced level.

I must end with a disclaimer. I do not wish to suggest that with our curriculum students will achieve the Advanced level within two years. Our experience at the University of Nebraska certainly has not borne that out. But this method does train students to retain in their memory and produce, both in oral and written form, larger German texts than typically are required in most second-year curricula. In this manner we are pushing students more systematically, and perhaps also more efficiently, toward Advanced-level performance. Long-range testing must be conducted to see what results this method yields. The research project we are currently conducting will address this ques-

8. The difference in comprehensibility of European and Native American tales ties into the emphasis on culture in the Standards and the revision of the ACTFL Proficiency scale. Moreover, the simple narrative structure typically found in children's literature speaks for its implementation in the foreign language curriculum, and also helps explain the enthusiastic reception it meets with among our students. 
tion. But the methodological considerations presented here will, I hope, contribute to the general discussion of learning goals, the criteria for selecting texts, and curricular design for second-year foreign language instruction.

\section{Works Cited}

Bernhardt, Elizabeth Buchter. "Toward an Information Processing Perspective in Foreign Language Reading." Modern Language Journal 68 (1984): 322-31.

Buck, Kathryn. The ACTFL Oral Proficiency Interview Tester Training Manual. New York: ACTFL, 1989.

Carrell, Patricia L. "Evidence of a Formal Schema in Second Language Comprehension." Language Learning 34 (1984): 87-112.

Davidheiser, James. "The ABC's of Total Physical Response Storytelling." The Odyssey Continues: Dimension 2001. Ed. C. Maurice Cherry. Valdosta, GA: Southern Conference on Language Teaching, 2001. 45-63.

Davidheiser, James. "Teaching German with TPRS (Total Physical Response Storytelling)." Die Unterrichtspraxis 35 (2002): 25-35.

Edwards, Alison L. "Reading Proficiency Assessment and the ILR/ACTFL Text Typology: A Reevaluation." Modern Language Journal 80 (1996): 350-61.

Horiba, Yukie. "Comprehension Processes in L2 Reading: Language Competence, Textual Coherence, and Inferences." Studies in Second Language Acquisition 18 (1996), 433-73.

Horiba, Yukie, Paul W. van den Broek, and Charles R. Fletcher. "Second-Language Readers' Memory for Narrative Texts: Evidence for Structure-Preserving Top-Down Processing." Bilingual Performance in Read- ing and Writing. Ed. Alister H. Cumming. Ann Arbor, MI: Language Learning/John Benjamins, 1994.43-71.

Janosch. Oh, wie schön ist Panama. Weinheim: Beltz and Gelberg, 2001.

Kintsch, Walter. Memory and Cognition. Malabar, FL.: Robert E. Krieger, 1982.

Kintsch, Walter, and Edith Greene. "The Role of CultureSpecific Schemata in the Comprehension and Recall of Stories." Discourse Processes 1 (1978): 1-13.

Lee, James F, and Diane Musumeci. "On Hierarchies of Reading Skills and Text Types." Modern Language Journal 72 (1988): 173-85.

Mandler, J. M. "A Code in the Node: the Use of a Story Schema in Retrieval." Discourse Processes 1 (1978): 14-35.

Mandler, J. M., and N. S. Johnson. "Remembrance of Things Parsed: Story Structure and Recall." Cognitive Psychology 9 (1977): 111-51.

Meyer, Bonnie J. F, and Roy O. Freedle. "Effects of Discourse Type on Recall." American Educational Research Journal 21 (1984): 121-43.

plauen, e. o. Vater und Sohn Bildgeschichten. Stuttgart: Reclam, 1994.

Thorndyke, Perry. "Cognitive Structures in Comprehension and Memory of Narrative Discourse." Cognitive Psychology 9 (1977): 77-110.

Trabasso, Tom, and Paul van den Broek. "Causal Thinking and the Representation of Narrative Events." Journal of Memory and Language 24 (1985): 612-30.

Tschimer, Erwin. "Oral Proficiency Base Lines for Firstand Second-Year College German." Die Unterrichtspraxis 25 (1992): 10-14.

van den Broek, Paul. “The Effects of Causal Relations and Hierarchical Position on the Importance of Story Statements." Journal of Memory and Language 27 (1988): 1-22. 